\title{
تطبيق طريقة شرفة المسرح والجلسة \\ في تعليم اللغة العربية لترقية مهارة الكلام بمدرسـة الثانوية المحفوظة
}

\author{
Labibatul Fachiroh, Muhammad Thohir \\ UIN Sunan Ampel Surabaya \\ labibatulf12@gmail.com
}

Article History:

Received:

08-06-2020

Revised:

16-06-2020

Accepted:

30-06-2020

\section{Keywords:}

Arabic, Speaking Skill, Gallery Session Method

\begin{abstract}
:
The title of this research is to apply the gallery session method in Arabic learning to improve speaking skills at the Madrasah Al-Machfudzoh Sidoarjo. Discuss how the implementation of the method in Madrasah AlMachfudzoh and its superiority in increasing students' speaking skills. Here, the researcher examines the extent of the role of the application of the gallery session method in Madrasah Al-Machfudroh, especially the 7th-grade Tsanawiyah, to improving the speaking skill. Here the researchers used descriptive qualitative methods. This research is library research that relies on a descriptive-analytical approach (al-manhaj al-washfi at-tablili). The descriptive approach is to analyze scientific material that is related to the subject, through library research and then presented and explained systematically. The results of this study show that the gallery session method has many advantages. Students are trained to understand the contents of reading and then be able to visualize it in the form of images to express it with communicative language then.
\end{abstract}

كان تعليم اللغة العربية واستيعابها أمرا ضروريا للمسلمين. وكثير من المسلمين في بلادنا

إندونيسيا هم يتعلمون اللغة العربية في مؤسسة رسمية كان أو غير رسمية نحو معاهد إسلامية. عندما يكون تعليم اللغة للطلاب فلابد من ايجاد التوازن بين المهارات اللغوية الأربع: الإستماع و الكلام والقراءة

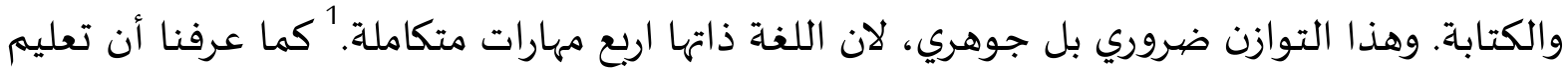
اللغة العربية لغير الناطقين بها يحتوي على أربع مهارات لغوية، وهي مهارة الاستماع ومهارة الكلام ومهارة

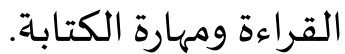

\footnotetext{
(الرياض: جامعة الملك سعود, 1988) تعليم اللغة: حالات وتعليقات ,محمد علي الخولي 1
} 
وفي الحقيقة الآن وجد أن كثيرا من عمليات تعليم اللغة العربية في إدارة المدارس مرتكزة على

المدرس. في هذا الموقف يكون المدرس مجرد معلم بمعنى أن المدرس يتحدث والدارسون يستمعون. أي أن علاقة الدارسين بمدرسهم مقصورة على الاستماع إليه واستقبال المعلومات ومحاولة إدراكها واستيعابها. ولا يوجد أى نوع من التفاعل بين الدارسين وبعضهم. والمدرس في هذا الموقف هو صاحب السلطة ودوره الإلقاء والنصح والإرشاد دون تفاعل مع الدارسين. ومن الواضح أن في هذا الحال يصبح الدارسون سائمين لاتباع التعليمات، وليس عندهم حماسـة عالية إلا لقضياء واجبات التعليم.2 وأما أهداف تعليم اللغة العربية وتدريسها تنقسم إلى قسمين: الهدف العام الذي يشتمل على الهدف اللغوي والمعرفي والهدف الخاص يشتمل على خمسـة أهداف وهي مهارة الإستماع والكلام والقرأة والكتابة ثم ترجمة. وللوصول إلى هذه الأهداف يحتاج على عدة الطرق التعليمية المناسبة لان الطريقة هي مجموعة الأساليب التي يتم بواسطتها تنظيم المجال الخارجي للمتعلم من اجل تحقيق اهداف تربوية معينة. كما قال محمود يونس بان الطريقة اهم من المادة لكن لتفهيم فى تعليم وتعلم ليس بطريقة فقط ولكن بالعوامل كالبيئة المدارس والكتب الدراسية كالمادة التعليمة وغير ذلك. وذالك ينبغي على المدرس ان يملك القدرة في اختيار الطريقة و وسائل التعليم المناسب. وللكلام منزلة كبيرة في الحياة فهو ضرورة من ضرورتها ولا يمكن للانسان أن يستغنى عنـه في اي حالة من حال عمره. ولا في اي مكان يقيم فياه، لانه وسيلة الإتصال بين الافراد في التبادل المصالح وقضاء الحاجات وتقوية الروابط الفكرية والإجتماعياة,وهو وسيلة الإبانة والإفصاح عما في نفس الإنسان وما يشعبربها وما يفكر فياء.

بالنسبة لمهارة الكلام، فإنها من أصعب المهارات تطبيقًا لدى متعِّميها لعدم البيئة اللغوية المتوّفرة بإندونيسيا، إذا هي إحدى المهارات التي يحتاج إلى الجهد والممارسـة والمثابرة، ولا يمكن اكتساب

\footnotetext{
2 Mochamad Hasyim, “" استخدام طريقة جيكسو في تعليم مهارة القراءة: بحث تجربي في مدرسة دار التقوى الثانوية الإسلامية بسينجون اجونج بورواساري (Universitas Islam Negeri Maulana Malik Ibrahim, 2014).

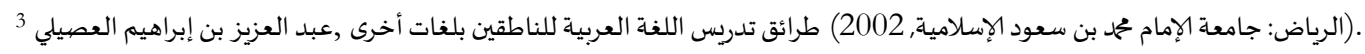

${ }^{4}$ Azhar Arsyad and Nurcholish Majid, Bahasa Arab Dan Metode Pengajarannya: Beberapa Pokok Pikiran (Pustaka Pelajar, 2010).
} 
هذه المهارة إلا بسعيهم في العملية التعليمياة. ولا تحلّ هذه المشكلات ايضيا إلا إذا قام المدرس باستخدم الطريقة الجيدة لتنظيم الطلاب عند الدراسة لكي لا يكون خائفين على لغة العربية ويستطيعون تكلما بلغة العربية. ومن أسـاليب المحادثة عرض الصورة، ومطالبة التلاميذ بالمحادثة عنها بالنظر الى الصيور التى تحكى أحداث القصية، واتا الفرصة للتلميذ كي يحكى ما سمع من قصص على زملائه ولا شك ان الناس يتحدثون اكثر مما يكتبون. والإنسان في تعامله مع الأخرين لابدله أن يتحدث اليهم وان يتحدثوا اليه وان يستمع الههم. وتتوقف جودة المحادثة عند التلاميذ على امور: حضور الأفكار والمعاني التي ستكون موضوعا للمحادثة, ومعرفة الكلمات التى تدل على تلك المعاني, وسهولة خطوره في البال، ومعرفة اسـاليب الكلام لترتيب العبارات من الكلمات وطلاقة اللسان في نطق الألفاظ.

قد عرفنا أنّ في العالم التربوي كثير من طرائق التعليم إما ان يكون محافظا على القديم أو معاصرا. وتلك الطرائق تستعمل في التعليم لغرض تسهيل وضيفة المعلّم في إرشاد الطلاب وتوجيههم إلى غرض التربية. والتربية هي السعي او النشاط الذي يعمل المرء بمرتب ومخطط بالمقصود تغيير او نشر العمل المراد.

وأما غرض التربية مقيّد في القانون الجمهورية الإندونيسيارقم 20 السنة 2003 الذي يعلن أنّ غرض التربية الوطنية فهو لينميّ قوّة الطلاب لكي يكون الطلاب المؤمنين و المتقين إلى الله ولهم الأخلاق الكريمة والصحة والعلم والقدرة والإبتكارى والمستقلّين بنفسهم والرعويّين الديمقرطيّة والمسؤلية. و وبهذا القانون لابد على المؤسسـة التربوي مثلا المدرسة الثانوية او المدرسة العالية ترقية في التربية الطلاب فيها. لكن المشكلات في تدريس اللغة العربية هي صعوبة تعليمها لانها لغة غريبة ومختلفة بلغة الأم اي لغة الأندونيسيية التي تستخدم كل يوم. نظرا إلى الحقيقة فينبغي للأسـاتيذ أن يهتموا بمهارة الطلاب خاصهة مهارة الكلام لأنها أهم مهارات لغوية، ولأنها أول ما يهدف متعلمو اللغة الأجنبية.

${ }^{5}$ Sorimuda Nasution, Didaktik Asas-Asas Mengajar (Bumi Aksara, 1995).

${ }^{6}$ Hasbullah, Dasar-Dasar Ilmu Pendidikan (Rajagrafindo Persada (Rajawali Pers), 2001). 
إن طريقة البحث التي استخدمتها الباحثة هي الطريقة الكيفية. البحث الكيفي المستخدم في هذه البحث لدياء الخصائص التالي : 1) استخدام القياس الكيفي إلى البيانات أو جمع المعلومات، 2) البيانات الكيفية صفاتا مفصلا نوعية في شكل حالات والناس والأحداث والتفاعلات والسلوكيات التي يمكن ملاحظتها، 3) وصفا ومفصلا تتعلق بالتلاميذ والمدرسين والتفاعل التعليمي وغرض التعليم والمواد التعليمية والأدوات والطرائق وتثقيف البيئة. وإن الطريقة الكيفية طريقة تحليلية ووصفية بإعتراب نوعي. الطريقة الكيفية العامة مستخدمة لجمع المعلومات وتقويمها. والتقويم هو الحصول المنتظم على البينات وتقويمها لتوفير إفادات عملية عن شيئ ما. 'فلذلك، استخدمت الباحثة في هذه الدراسة على المنهج الوصفي التحليلي الذي يوصف ويقوم، وذلك بوصف الظاهرة التي يريد دراستها وجمع أوصاف ومعلومات دقيقة عنها. ولذلك فإن المنهج المتبع في هذا البحث هو المنهج الوصفي التحليلي. واختارت الباحثة هذا المنههج لأنه يناسب مع طبيعة الدراسـة. وعلى ضوء هذا المنهج تقوم الباحثة بوصف وتحليل تطبيق طريقة شرفة المسرح والجلسة (Gallery Session) في تعليم اللغة العبية لترقية مهارة الكلام بمدرسة الثانورية المحفوظة جابون سيدو وارجو. التي تستند على كيفية تطبيقها للصف السابعة الثانوية في هذه المدرسة. وهو يوصف ويفسر ما فيه من الأشياء والظواهر التي يتناولها البحث ثم التحليل عن كيفية تطبيقها تحضر الباحثة في مدرسـة المحفوظة لأن في هذا البحث الكيفي تقوم الباحثة أدواة البحث فرديا وتستطيع لتناول البيانات وغيرها كادوات البحث لابد الباحثة أن تختار المصادر البيانات، وطريقة جمع اليانات، وطريقة تحليل البيانات والإستنتاج والمراجع. وأما ميدان البحث هي المدرسة الثانوية المحفوظة كيدونج جانكرينج جابون سيدوارجو خصوصا في الصف السابع. في هذا البحث أخذت الباحثة البيانات

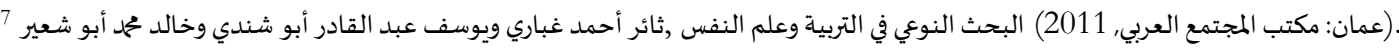

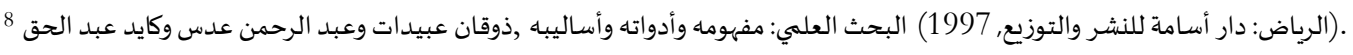


بوسيلة الملاحظة، والمقابلة، والوثائق عن تعليم اللغة العربية من خلال تطبيق طريقة شرفة المسرح والجلسـة (Gallery Session) فى تعليم اللغة العربية لترقية مهارة الكلام بمدرسة الثانوية المحفوظة جابون سيدو وارجوخصوصيا في الصف السابع. عينية هذه البحث هو الطلبة من الصف السابع في المدرسة الثانوية المحفوظة كيدونج جانكرينج جابون سيدوارجو ومعلم اللغة العربية (الأستاذة نور المصلحة الحاجة) ورئيس المنهج الدراسي في المدرسـة الثناوية المحفوظة كيدونج جانكرينج جابون سيدوارجو. وأتمنى هذا البحث مفيد وقادر في إعطاء نظرة عامة، تحاول الباحثة بتصميم شكل ترقية مهارة اللغة العربية خصوصا مهارة الكلام من خلال تطبيق تطبيق طريقة شرفة المسرح والجلسـة (Gallery Session) في تعليم اللغة العربية لترقية مهارة الكلام.

\author{
نتائج البحث ومناقشتها \\ مهارة الكلام وأهمية تدريسها وأهداف تدريسها
}

والكلام هو مهارة ثانية بعد مهارة الإستماع في تدريس اللغة العربية وهو جزأ من التعبير الوظيفي

من حيث الخطب وإصلاء التعليمات وكتابة التفارير، والمذكرات والملخصات وانتشرت والإعلانات وتحرير الرسـائل وما إلى ذلك.

وبجانب ذلك قال الدكتور عبد المجيد أحمد منصيور أن الكلام هو الشكل الرئيس للإتصال

الإجتماعى عند الإنسان، ولهذا يعتبر أهم جزء في ممارسة اللغة واستخدامها. 10 أكد ذلك الرأي بقول أحمد عبد الله بشيربأن مهارة الكلام هي إنتاجية تطلب من المعلم القدرة على استخدم الأصيوات بدقة والتمكن من صيخ النحوية ونظام الترتيب الجمل والكلمات حتى تساعدعلى التعبيرعما يريده المتكلم في موافق الحديث. 11

\footnotetext{
(القاهرة: دار المعارف, 1983) التوجهية في اللغة العربية ,محمود على السمان 9.

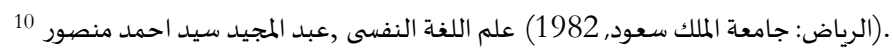

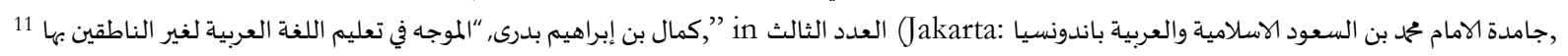
n.d.).
} 
أن مهارة الكلام هي من إحدى المهارات اللغوية المستخدمة كألة التفهم بين المتحدث والسامع

عما يعبران من أذهانها مباشرة بأصوات اللغة بمراعة على الصيخ النحوية والترتيب الجمل والكلمات. الكلام هو النشاط اللغوي المهم في الحياة اليومية كان الإنسان بـه يحاول أن يعبر عن كل ما خطر بباله من الأفكار والشفوي إلى غير شفويا. قال الرشدي أحمد طعيمة والكلام هو اللغة الثانية من المهارات الأساسية التي تمثيل غاية من غايات الدراسية اللغوية، وإن كان هو وسيلة للإتصال مع الأخرين. فكانت مهارة الكلام هي المهارة الأسـاسية الثانية بعد مهارة الإستماع، وتستعمل مهارة الكلام على المحادثة والتعبير الشفههي.

قال الدكتور محمد كامل الناقة في كتابه أنّ أهمّية مهارة الكلام هي: 1. إنّ الأسرة عندما تعلّم أبنائها لغة أجنبية أنما تتوقّع أن يتحدث 2. إنّ الكبير عندما يقبل على تعلّم اللّغة ما يكون التحدث في مقدمة أهداف 3. إنّ النجاح في تعلّم الكلام باللّغة الأجنبية يدفع على تعلّمها وإتقا. 4. إننا لا نتصور إمكانية الاستمرار في تعلّم القراءة والكتابة باللّغة الأجنبية دون التحديث. 5. إنّ الفرد عندما يقرأ ويكتب أنما يفكّر بواسطة ما تعلّمها سفوي، استماعا وحديثا. 6. إنّ عملية التعلّم اللّغة والاستفادة من المعلّم تعتمد على الحديث فالمعلّم في تدريسه وتصحيحها أخطاء الدارسين يستخدم الكلام، وهو عندما يصحح كتابات الدارسين أنما يناقسهم في ذلك شـفويّا. 12 وقال إبراهيم محمد عطا أما أهداف تعليم مهارة الكلام فكمايلى: 1. تعويد التلاميذ التفكير المنطقي وترتيب الأفكار و ربط بعضها بعضا. 2. تعويد التلاميذ إجادة النطق وطلاقة اللسان وتمثيل المعاني. 3. دعم تفاوت طبقات الكلام في اللسان العربي ببحسب تفاوالدلالة على تلك الكيفيات.

\footnotetext{
12 (مكة مكرمة: جامعة أم القرى, 1985) تعليم اللغة العربية للناطقين بلغات اخرى ,محمود كامل الناقة
} 


\section{4. تنمية الثقفة باالنفاس من خلال مواجهة زملائه الفصل أوالمدرسة أوخارج المدرسـة.}

5. تمكين التلاميذ من التعبير عما يدور حولهم من موضوعات ملائمة ,تتصل بحيام وتجارم و أعمالهم

$$
\text { داخل المدرسة وجارجها في عبارة سليمـة. }
$$

6. زيادة نموالمهارات والقدرات التى بذات تنموا عند التلميذ في فنون التعبير الوظيفى من مناقشـة

$$
\text { وعرض للأفكاروالأراء وإلقاء الكلمات والخطب. }
$$

7. الكشف عن الماهر بين التلميذ في مجال الخطابة والإرتجال وسرعة البيان فى القول والسداد في الأداء

والدقة في الأفكار.

8. ذيب الوجدان والشعور لذى المتعلم ليصبح فردا جماعته القومية الإنسانية.

9. دفع المتعلم الى ممارسة التخيل والإبتكار 13

وقال علي أحمد مشكور أنّ من أهم أهداف تدريس الكلام التي يجب أن يعمل المنهج بما فيه

المدرس على تحقيقها خاصة في المرحلة الأولى من مراحل التدريس العام هي كما يلي:

1. تطور و رعي الطّّل بالكلمات الشفوية كالوحدات اللّغوية.

2. 2 إثراء ثروته اللّفظية الشفهية.

3. تقويم روابط المعنى عنده.

4. تمكيناه من تشكيل الجمل وتركيبها.

5. تنمية قدرته على تنظيم الأفكار في وحدات لغوية.

6. تحسين هجائه ونطقه.

7. - استخدامه للتعبير القصصي المسلي 14

ومن هنا، فنظرت الباحثة أنّ أهداف تدريس الكلام هي أن ينطق التلاميذ بلفظ صحيح الذي

يوافق الصيغة النحوية وليعبرما في ذهن وفكر بنظام اللّفظ وبالتركيب الصحيح.

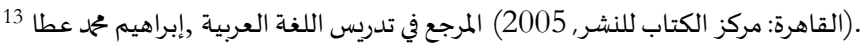

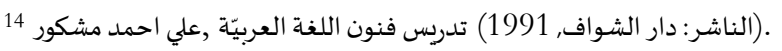


50 | Volume 11, Nomor 1, Juni 2020

تنقسم مهارة الكلام إلى قسمين:

1. المحادثة: أما المحادثة فهي الكلام في المواقف الإتصالية غير المعدة, وعادة ما يبداء المتعلم إستخدام

هذه الاسلوب باسئلة منـا وإجابات قصيرة من الطلاب.وتأتي أهمية المحادثة باعتبارها الأسلوب الطبعي

للتعامل في الحياة فالناس يتحدثون اكثر مما يكتبون، والإنسان في تعامله مع الأخرين لابد لله ان يتحدث إليهم وان يتحدثوا إلياه وان يستمع اليهم. المحادثة هي المناقشـة الحرة التلقائية التى تجرى بين فردين حول موضهوع معين. وفي هذا التعريف تستوفقنا النقاط الحاكمة Key Words الأتية: المناقشـة، الحرة، التلقائية، فردين، موضوع ولكل هذه النقاط تطبيقه التربوي في هذا المجال: أ. المناقشـة: المحادثة مناقسـة, معنى هذا ان من أشكال الإتصيال اللغوي الأخرى ما لا يعتبرمحادثة، وان كان شفهيا كالمحادثة. من هذه الأشكال مثلا: أن يلقي متحدث كلمة في لقاءما. منها غيرها من مجالات الحديث الشفوي مما نخرجه من نطاق المحادثة لسبب واحد وهو أنها تفتقر إلى روح المناقشـة ومتطالبتها ب. الحرة: ومعنى هذا ان المحادثة لا تتم قسرا ولا تحدث إجبارا. أن حرية المتحدث شرط لحديثـ وعندما يفتقد هذا الشرط يصبح ما يقوله المتحدث ترديدا أو إملاءا عليه من الأخرين ج. التلقائياة: والمحادثة عملية تلقائية يترك الفرد فيها على سجيتاه، فيستخدم من الوان الحديث ما يطيب له وما يقدر عليه. الاتصال الكاملبين البشر امر لا وجود له. والتلقائية هنا تعني، ضمن ما تعنيه ان ثمة متغيرات كثيرة تحكم عملية الكلام وتجعله يسير بشكل معين قد لا يتوقعاه السامعون.

د. فردان: المحادثة ظاهرة اجتماعية، والذين يطلقون كلمة المحادثة على الحوار الداخليالدائر في عقل الإنسان عندما يتحدث فانما يطلقون الكلمة من قبيل المجاز. والمحادثة إذن نشاط يدور بين فردين. معنى هذا ان لكل منهما حقوقا وعليه واجبات. وبقدرما نصفمتحدثا معينا باناه متحدث جيد, نستطيع ايضيا ان نصف مستمعا معينا باناه مستمع جيد. 
15

هو.موضوع:واخيرا فالمحادثة تدور حول موضوع

2. التعبير الشفهي: التعبير لفظا هو الإبانة والإفصاح عما يجول في خاطر الإنسان من أفكار ومشاعر وأحاسيس بحيث يفهما الأخرون. واما التعبيرإصطلاحا هو العمل المدرسي المنهجي الذي يسير وفق خطة متكاملة.للوصول إلى مستوى يمكناه من ترجمة افكاره ومشاعره واحاسيسـاه ومشاهداتاه وخبراتاه الحياتية شفاهيا بلغة سليمة، وفق نسق فكري معين. 16 وتتوقف جودة التعبير الشفوي عند التلاميذ على أمور كما يلي: 1. حضور الأفكار والمعاني التي ستكون موضيوعا للحديث 2. حسن تيبها في الذهن 3. معرفة الكلمات التي تدل على تلك المعاني 4. سهولة خطورها في البال 5. معرفة اسـاليب الكلام لترتيب العبارات من الكلمات 6. طلاقة اللسان في نطق الألفاظ

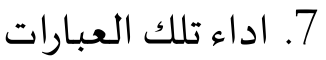

وللتعبير الشفوي صهورة كثيرة نعرض بعضها في ما يلي: 17



2. التعبير عند الصورة التي يجمعها التلاميذ، أو يعرضها عليهم المعلم أو صهور التي بكتب القراءة 3. التعبير الشفوي عقب القراءة، بالمناقشة والتعليق والتلخيص والإجابة عن الأسئلة 4. إستخدام القصص في التعبير بالصور الأتية: - - تكميل القصص الناقصة

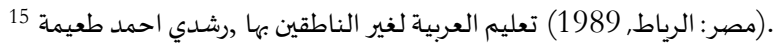

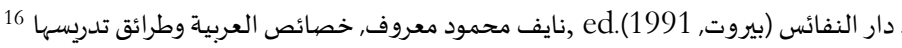

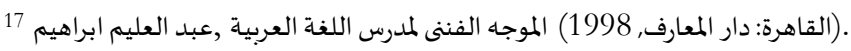


52 | Volume 11, Nomor 1, Juni 2020

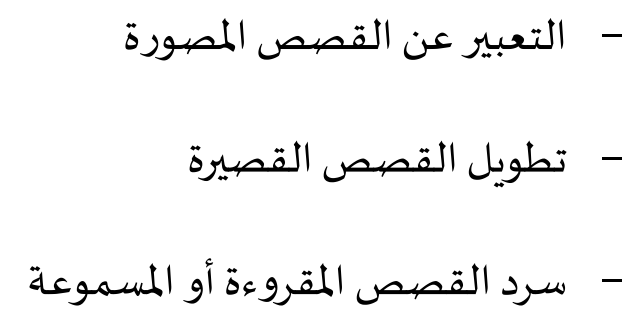

5. حديث التلاميذ عن حياتهم ونشاطهم داخل المدرسة وخارجها (خصص الألعاب والرسم والإشغال

$$
\text { 6. مملكة الحيوان والنبات والطير }
$$

7. الحياة: طبيعتها وأعمال الناس فيها. وما يجد فيها من الإحداث (الحدائق والمزارع والصحاري ومظهر

$$
\begin{aligned}
& \text { الفصول المختلفة والبيئات والفلاح وسـاعي البريد والجندي) } \\
& \text { 8. الموضيوعات الخلقية والإجتماعية والوطنية والإقتصيادية } \\
& \text { 9. الخطب والمناظرات }
\end{aligned}
$$

\section{طريقة شرفة المسرح والجلسة (Gallery Session) وتطبيقها}

أما تعريف طريقة شرفة المسرح والجلسة ${ }^{18}$ (Gallery Session) هي أحد طرائق التدريس اللغة التى

يتمكن أن نؤدي المى الموارد العاطفي الطلاب. أما Gallery هي النشاط ليعرف النتاج أو المحصول أو شغل للأخرين. 19 وأما Session هي الإتصالي بين الشخصين م. وتريد من هذه الطريقة أن توقع الإتصالي في وقت الدراسـة. إستخدام هذه الطريقة لتدريب كفاءة الطلاب في فهم المقرؤ ثم يقدرون على التصهوربالصيورة وتريد من هذه الصيورة أن يتحدث بينهم بأن يكون الطلاب يسألون على اصدقائهم الأخرين مما يبصرون مباشرة.

\footnotetext{
${ }^{18}$ Elias Antoon Elias, Modern Dictionary, English-Arabic (Elias’ Modern Press, 1954).

${ }^{19}$ John M Echols and Hasan Shadily, "Kamus Indonesia-Inggris" (2019).

${ }^{20}$ Ibid.

${ }^{21}$ Imam Makruf, Strategi Pembelajaran Bahasa Arab Aktif (Need's Press, 2009).
} 
الصورة تساعد الطلاب على التكلم بلغة العربية سهولة، لانهم يتفكرون ما سيتصورون في الصورة أولا ويفهمون ما فيها. يطلب الطلاب على اشراحها عند يسأل الأخر منها. وهناك لا يسأل الطلاب عما هو موجود في الصورة وإنما التحدث عن جوانب غير مرئية في الصورة أم ما يتخيل الدارس ان الصورة توحي به. 22 فمثلا في هذه الصورة يشاهد الطالب سيارة مطافئ تسير في الشوارع. لكنه لا يعرف إلى اين يذهب رجال المطافع ءالان، ومن اتصل بهم,وكيف شب الحريق، وهل الحريق في مكان تجاري ام صناعي

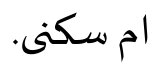
تساعد الصورة الطلاب على تمييز الكلمات والأفكار كما أهها تسهل عليهم ربط الكلمات بما تشير الياء. ويستطيع المعلم أن يصمم التمارين التى تساعد المتعلمين على تطوير تهجئتهم من خلال استخدام الرسومات الخطية. ويستطيع المعلم أن يجمع بمساعدة الطلاب عددا من الصهور من المجلات والجرائد

يستطيع المعلم أن يجعل من التعبير المصور بوصفه تدريبا شفويا موجها نشاطا كتابيا يعقب

مرحلةالتدريب الشفوي. ويجد المعلم نفسـه عند استخدام الصور التعبير الشفوي خيارين. الخيار الأول أن يستخدم المعلم صورا معدة مسبقا مثل الصيور التجارية الجاهزة وفي هذه الحالة يستحسن أن تتعلق الصور على السبورة أمام الفصل اثنأ الدرس ويتكلم الطلاب منها. والخيار الثاني هو أن يقوم المعلم برسم الصيور بنفسـاء, وهي عادة تكون عبارة عن رسومات تخطيطية بسيطة. يحبذ أن يسجع المعلم الطلاب على المشاركة بفعالية منذ بداية الحصة وذالك بأن يقوم هو مثلا برسم الصورة الأولى من مجموعة الصور المكونة للقصة ثم يتقدم الطلاب بطائفة من الاسئلة عن محتويات الصيورة و يكتب الكلمات الأسـاسيسة والتعبيرات التى يقترحها الطلاب وبعد ذالك يسال الطلاب عن توقعاتهم عما سيحدث بعد ذالك. والطالب يستطيع ألن يستنتج الفكرة الجيدة عند التكلم. 24

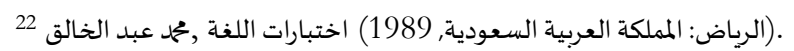

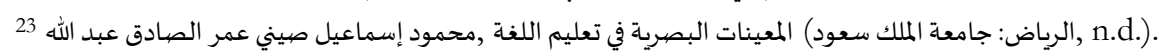

24 Ibid.
} 
54 | Volume 11, Nomor 1, Juni 2020

هذه الطريقة هي من أحد استراتيجية التدريسي لإعطاءا لطلاب عن مشكلات و تجب عليهم أن

تخللها بالمجموعة. نشأت هذه استراتيجية من فكرة جون ديوي ل على أن Jonh Dewey هي عملية التعليمياة بفعل خطى معينة وموافق على أهدافها. وتدخل هذه استراتيجية في نظرية Kontruktivisme ويفهم من هذه النظرية بان الطلاب يجعل بيئة الدراسية بنفسـا. اعطى المدرس الفرصة للطلاب لتطور مهارتهم مثلا بالكتابة و التجربة والمحادثة وعند رأي سيلبيرمين Silberman هذه استراتيجية أحد طرق ليثمن وتذكر ما تعلماه اللطلاب. هذه الطريقة يسبب الطلاب ليتعلمون بفعلي. عملية التعليمية الفعلية هي أشرع خطوات وأفرح ويعضده.

قال سيلبيرمين "عملية التعليمية الفعلية هي اتحاد جامعة الاستراتيجية التعليمية الشاملية".

عملية تعليمية الفعلية تشتمل على طرق لجعل الطلاب فعليا من بداية الدراسـة الى أخرها بحيوية في المجموعة. 25 أما مركز تعليمية الفعلية هي لجعل أحوال الطلاب على أن يستطيعوا استخداما الوقت الدراسة للتعلم. وعند رأي سيلبيرمين فكرة تعليمية الفعلية موافق على أظهار Conficus القائل:

$$
\text { كل شيء استمع فنسيت شيء اشهد فيء ئذكرت }
$$

تدل هذه الفكرة أن في التعليمية يحتاج على الحس إذا كان أعضياء الطلاب كثيرا الإشتراك في نشاط التعليمية فيطول الأثر وفهم الطلاب على مادة التدريس. خطوات طريقة شرفة المسرح والجلسة(Gallery Session) أما خطوات هذه استراتيـية فكما يلي : 1. قسم المدرس الطلاب الى عدة مجموعات تتكون من ثلاثة أو أربعة الأشخاص 2. قدم قرطاس بلانو للمجموعة

${ }^{25}$ Makruf, Strategi Pembelajaran Bahasa Arab Aktif.

${ }^{26}$ L Melvin, “Active Learning: 101 Cara Belajar Siswa Aktif” (2016).

Program Studi Pendidikan Bahasa Arab Universitas Yudharta Pasuruan https://jurnal.yudharta.ac.id/v2/index.php/studi-arab 


\section{3. يعين المدرس المادة التي سيبحث في الدراسـة \\ 4. أعطى المدرس النصوص أو المقروء المختلفة}

5. يجب لكل شخص في مجموعاه أن يقرأ ويفهم النصوص أو المقروء بالجماعاة

6. يأمر المدرس لكل مجموعة أن تتصور ما تفهم في النصوص أو المقروء بالصهورة تعبر فكرتهم نحو

المقروء

7. يضع الطلاب الصبورة في الجدار او السبورة او المعرض المستعد وان لم يكن ذالك فلابأس يوضيع

خارج الفصل

8. ويشير رئيس المجموعة أحد أعضائها ليكون حارث الصورة في المعرض. واما وظيفة الحارس هي شرح الصورة لكل الزائر الذي يسأل ما في الصورة او المقاصيد عن الصورة الموضوعة

9. للأخرين هم الطلاب الذين لايحرسون المعرض أن يجولوا الى كل المعرض او الصيورة ويسألوا

الحارس عما يتعلق بالصورة باللغة العربية.

10. ولابد لكل الحارس ان يشرح المقصود في الصورة باللغة العربية ايضا ثم يتبادل الطلاب في هذه

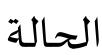

11. وفي انتهاء الوقت يعود الطلاب الى جلوسهم ويعطى المدرس التوضيح والإستدلال والتقويم في

$$
\text { آخر الدراسـة27 - 20 }
$$

أهد اف هذه طريقة شرفة المسرح والجلسـة(Gallerry Session)

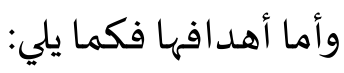

$$
1 \text { ـ توسيع خيال الطلاب وتربى في وجدانهم وتنمى ذاكرتهم وتقوى حافظتهم }
$$

2. تطبع على حسن الفهم وحسن الفهم أسـاسا لحسن الكلام والتعبير عما يحول في النفس من

$$
\text { الإحساس والإفكار }
$$

\footnotetext{
${ }^{27}$ Makruf, Strategi Pembelajaran Bahasa Arab Aktif.
} 
3. تأثير شوق إلى التعليم وتحبيبا في اللغة العربية

$$
\text { 4. 5. تشجيع الطالب على مواجهاة الأخرين ومحاورتهم بلغة عربية سليمة }
$$

مزايا هذه طريقة شرفة المسرح والجلسة(Gallery Session) إعتاد الطلاب لبناءثقافة للتعاون من أجل حل المشاكل في التعلم

1. تنمية الثقفة با النفاس من خلال مواجهة زملائك الفصل أوالمدرسـة أوخارج المدرسـة

2. قدرة التلاميذ على التعبير عما يدور حولهم من موضوعات ملائمة ,تتصل بحياتهم وأعمالهم

$$
\text { داخل المدرسـة وخارجها بعبارة سليمة. }
$$

3. زيادة نموالمهارات والقدرات التى بذات تنموا عند التلميذ في فنون التعبير الوظيفى من مناقشة

$$
\begin{aligned}
& \text { وعرض للأفكاروالأراء وإلقاء الكلمات والخطب. } \\
& \text { 4. معرفة الكلمات التي تدل على تلك المعاني } \\
& \text { 5. سهولة خطورها في البال } \\
& \text { 6. معرفة اساليب الكلام لترتيب العبارات من الكلمات }
\end{aligned}
$$

7. التغلب على عامل الحياء الزائد عند بعض الطلاب الذي يحول دون توضيح الأفكار والمعاني التي

$$
\text { تجول في خواطرهم }
$$

عيوب هذه طريقة شرفة المسرح والجلسـة(Gallery Session)

1. بالغت في مفهوم العلاقة المباشرة بين الكلمة والشيئ وبين العبارة والفكرة, واهتمت بالمفردات,

واهملت دراسة التراكيب النحوية, وهذا مما يؤدي إلى فقدان التوازن بين عناصر اللغة.

2. هذه الطريقة لا تصلح للفصول الدراسية ذات الأعداد الكبيرة من الطلاب, بل ينبغي ال يتعدى

$$
\text { عدد الطلاب الفصل عشرين طالبا }
$$

\footnotetext{
28 مكتب غريب, n.d.).
} 
3. إذا كان اعضياء المجموعة كثيرا يحدث لشنق الطالب الجزء عمل الصديق

4. تحاشي تصيويب الأخطاء الذي يعد من مزايا هذه الطريقة,قد يؤدي إلى استساغة الطلاب لهذه الأخطاء وربما يقود إلى تحجرها.

5. هذه الطريقة لا تراعي الفروق الفردية بين المتعلمين, لانها تهتم بالجوانب الإنسانية في المهارات

الشفهية.

6. حينما كان الارتباط بين المعلم والمتعلم لم يكن خيرا كالقلق والخوف وغير ذلك سيؤثر موضوعي

الحاصل.

7. الأسئلة التي يقدمها الاخر بين المتعلمين أحيانا لاتساوي جودًة ,إما درجة صعوبته مرتفعة في

حين وإما منخفضية في حين آخر.

الخلاصية

إن تطبيق طريقة شرفة المسرح والجلسـة لترقية مهارة الكلام بمدرسة الثانويـة المحفوظة جابون

سيدو وارجو خصوصا في الصف السابع جيد. يتكلم الطلاب بالحر وبالسعادة لأههم يتكلمون مع

أصدقائهم عما يفهمون من الصورة, هم يستطيعون أن ينتجوا فكرتهم عند التكلم. ولكن توجد المزايا

والعيوب في تطبيقها نحو قدرة التلاميذ على التعبير عما يدور حولههم من موضوعات ملائمة ,تتصل

بحياتهم و أعمالهم في المدرسة وغيرها بعبارة سليماة، وزيادة نموالمهارات والقدرات التى بذات تنموا عند

التلميذ في فنون التعبير الوظيفى من مناقشة، وعرض للأفكار والأراء وإلقاء الكلمات والخطب وأما عيوب

تطبيقها منها : بالغت في مفهوم العلاقة المباشرة بين الكلمة والشيئ وبين العبارة والفكرة, واهتمت بالمفردات, واهملت دراسـة التراكيب النحوية،, وهذا مما يؤدي إلى فقدان التوازن بين عناصر اللغة، الأسئلة التي يقدمها الاخر بين المتعلمين أحيانا لاتساوي جودًة ,إما درجة صعوبته مرتفعة في حين وإما منخفضية 
في حين آخر وغير ذلك. فينبغي على مدرس اللغة العربية أن يرقي حماسة المعلمين في تجديد عملية التعليم والتعلّم خاصةة في الطريقة التعليمية (شرفة المسرح والجلسة مثلاً) لترقية مهارة الكلام.

Arsyad, Azhar, and Nurcholish Majid. Bahasa Arab Dan Metode Pengajarannya: Beberapa Pokok

Pikiran. Pustaka Pelajar, 2010.

Echols, John M, and Hasan Shadily. "Kamus Indonesia-Inggris” (2019).

Elias, Elias Antoon. Modern Dictionary, English-Arabic. Elias’ Modern Press, 1954.

Hasbullah. Dasar-Dasar Imu Pendidikan. Rajagrafindo Persada (Rajawali Pers), 2001.

Hasyim, Mochamad. “ استخدام طريقة جيكسو في تعليم مهارة القراءة: بحث تجريبي في مدرسة دار

التقوى الثانوية الإسلامية بسينجون اجونج بورواساري باسوروان جاوى الشرقية.” Universitas

Islam Negeri Maulana Malik Ibrahim, 2014.

Makruf, Imam. Strategi Pembelajaran Bahasa Arab Aktif. Need's Press, 2009.

Melvin, L. “Active Learning: 101 Cara Belajar Siswa Aktif” (2016).

Nasution, Sorimuda. Didaktik Asas-Asas Mengajar. Bumi Aksara, 1995.

ابراهيم, عبد العليم. الموجاء الفننى لمدرس اللغة العربية. القاهرة: دار المعارف, 1998

الحق, ذوقان عبيدات وعبد الرحمن عدس وكايد عبد. البحث العلمي: مفهوماه وأدواته وأسـاليبه. الرياض:

دار أسامة للنشر والتوزيع, 1997.

الخالق, محمد عبد. اختبارات اللغة. الرياض: المملكة العربية السعودياة, 1989.

الخولي, محمد علي. تعليم اللغة: حالات وتعليقات. الرياض: جامعة الملك سعود, 1988

السمان, محمود على. التوجيهة في اللغة العربية. القاهرة: دار المعارف, 1983.

العال, عبد المنعم سيد عبد. طرق تدريس اللغة العربية. مكتب غريب , n.d.

العصيلي, عبد العزيز بن إبراهيم. طرائق تدريس اللغة العربية للناطقين بلغات أخرى. الرياض: جامعة

2002, الإمام محمد بن سعود الإسلاميية, 
الله, محمود إسماعيل صيني عمر الصادق عبد. المعينات البصرية في تعليم اللغة. الرياض: جامعة الملك سعود, n.d.

الناقة, محمود كامل. تعليم اللغة العربية للناطقين بلغات اخرى. مكة مكرمة: جامعة أم القرى, 1985 العدد الثالث In بدرى, كمال بن إبراهيم. “الموجاه في تعليم اللغة العربية لغير الناطقين بها. Jakarta: جامدة الامام محمد بن السعود الاسلامية والعربية باندونسيا , n.d.

شعير, ثائر أحمد غباري ويوسف عبد القادر أبو شندي وخالد محمد أبو. البحث النوعي في التربية وعلم النفس. عمان: مكتب المجتمع العربي, 2011.

طعيمة، رشدي احمد. تعليم العربية لغير الناطقين بها. مصر: الرياط, 1989.

عطا, إبراهيم محمد. المرجع في تدريس اللغة العربية. القاهرة: مركز الكتاب للنشر, 2005.

مشكور, علي احمد. تدريس فنون اللغة العربيّة. الناشـر: دار الشـواف, 1991.

دار النفائس. بيروت, Edited by معروف, نايف محمود. خصيائص العربية وطرائق تدريسها. 1991.

منصيور, عبد المجيد سيد احمد. علم اللغة النفسى. الرياض: جامعة الملك سعود, 1982 
60 | Volume 11, Nomor 1, Juni 2020 